\title{
A literatura e o desenvolvimento da consciência crítica: um estudo sobre os impactos da leitura de "Redemoinho em Dia Quente" na equipe executora de um projeto de extensão
}

\author{
Literature and critical consciousness development: a study on the \\ impacts of the reading of "Redemoinho em Dia Quente" on the staff of \\ an extension project
}

\author{
Matias Collaço Scolaro ${ }^{1}$ \\ Leonardo da Silva² \\ Lavinya Carrazoni Fagundes ${ }^{3}$
}

\begin{abstract}
Resumo
Este artigo busca investigar o papel da literatura no desenvolvimento da consciência crítica (FREIRE, 1989). Mais especificamente, objetivamos compreender os efeitos da leitura de uma obra literária entre os participantes da equipe executora do projeto de extensão "Nas Entrelinhas: literatura de autoria feminina no presídio feminino de Itajaí - SC" do Instituto Federal de Santa Catarina. Para tanto, realizamos uma entrevista semiestruturada por meio de um grupo focal que incluiu discentes, docentes e voluntários do projeto. O objetivo deste encontro foi de dialogar e refletir - a partir de perguntas norteadoras desenvolvidas pelos pesquisadores - sobre o livro "Redemoinho em dia quente", de Jarid Arraes (2019). 0 encontro do grupo focal foi gravado e as falas dos participantes foram transcritas. A partir de uma análise temática dos dados, foi possível identificar oito temas emergentes que evidenciam aspectos importantes sobre a interação dos participantes com a obra. De forma geral, pudemos perceber que (1) os participantes puderam refletir sobre sua vida e sobre questões sociais a partir da leitura da obra, e que (2) o próprio encontro de discussão oportunizou, por meio do diálogo e da troca, a possibilidade de expandir visões e reflexões sobre os temas suscitados pela leitura.
\end{abstract}

Palavras-chave: Consciência crítica. Leitura crítica. Literatura escrita por mulheres.

\section{Abstract}

This article aims at investigating the role of literature in critical consciousness development (FREIRE, 1989). More specifically, our objective is to understand the effects of the reading of a literary work among the staff of the extension project "Nas Entrelinhas: literature authored by women in the female prison of Itajai - SC", promoted by the Federal Institute of Santa Catarina. To do so, we conducted a semi-structured interview via a focus group with the staff of the project (including students, teachers and volunteers who are part of it). The objective of the focus group was to create dialogue and promote reflection starting from guiding questions designed by the researchers - on the book "Redemoinho em dia quente", by Jarid Arraes (2019). The meeting was recorded and later transcribed. Based on a thematic analysis of the data, it was possible to identify eight emergent themes which highlight important aspects of the participants' interactions with the book. In general, we could observe that (1) the reading of the book allowed participants to reflect on their lives/experiences and on social issues, and that (2) the actual focus group created the possibility for dialogue and exchange to take place, allowing participants to expand their views and reflections on the themes brought up by their reading of the book.

Keywords: Critical consciousness. Critical reading. Literature authored by women.

\footnotetext{
1 Bolsista de Iniciação Científica Júnior do CNPq. Instituto Federal de Santa Catarina, Itajaí, Santa Catarina, Brasil. Orcid: https://orcid.org/0000-0002-3681-0609 E-mail: matias.cs21@aluno.ifsc.edu.br.

2 Doutor em Inglês: Estudos Linguísticos e Literários. Instituto Federal de Santa Catarina, São José, Santa Catarina, Brasil. Orcid: https://orcid.org/0000-0001-7346-5966 E-mail: leonardo.silva@ifsc.edu.br.

3 Bolsista de Iniciação Científica Júnior do CNPq. Instituto Federal de Santa Catarina, São José, Santa Catarina, Brasil. Orcid: https://orcid.org/0000-0002-4104-6967 E-mail: lavinya.f@aluno.ifsc.edu.br.
} 


\section{Introdução e fundamentação teórica}

Para Candido (1995), a literatura tem papel fundamental no processo de humanização. 0 autor defende que 0 acesso à literatura deve ser reconhecido, portanto, como um direito humano básico. Neste estudo, temos como objetivo principal investigar o papel da literatura no processo de reflexão e desenvolvimento da consciência crítica no contexto de um projeto de extensão envolvendo leitura. Para tanto, partimos da compreensão freireana de que a leitura da realidade precede o processo de alfabetização, visto que esse vai além da decodificação de letras e códigos. A ótica freireana de que a "leitura do mundo precede a leitura da palavra" (FREIRE, 1989, p. 9) nos traz o entendimento de que as experiências existenciais que rondam o cidadão já fazem parte do processo de leitura do mundo e da prática da racionalidade antes mesmo da alfabetização. Isso quer dizer que ler, desta perspectiva, não é apenas compreender a palavra, mas também compreender o mundo. Entendemos, portanto, que a literatura tem papel importante no processo de humanização, conforme defende Candido (1995), e no desenvolvimento de uma consciência crítica que possibilite melhor compreender a realidade, conforme postula Freire (1989).

Neste sentido, a literatura não é apenas um elemento ou um produto presente em nossa cultura, já que ela representa e constrói realidades, caracterizando-se como uma "manifestação universal de todos os homens em todos os tempos" (CANDIDO, 1995, p. 174). Ao mesmo tempo, é preciso destacar que consideramos neste presente estudo a literatura como "todo toque poético, ficcional ou dramático em todos os níveis de uma sociedade, em todos os tipos de cultura, desde o que chamamos de folclore, lenda, chiste, até as formas mais complexas e difíceis da produção escrita das grandes civilizações" (CANDIDO, 1995, p. 176), distanciando-nos então de uma visão elitista ou hierárquica.

Conforme Perissé (2007), a palavra atua como formadora de realidade e, ao mesmo tempo, é construída a partir da realidade. Ainda de acordo com 0 autor, a palavra expressa pelo homem forma também o seu contexto, em uma relação mútua entre criação e compreensão da realidade. Desta forma, compreendemos que a palavra tem papel fundamental na própria expressão humana. Em sintonia com Freire (1989), Perissé (2007) nos ajuda a compreender que a leitura da palavra vai além de apenas compreender a sua realidade para também construir a própria realidade.

De acordo com Compagnon (2009), "a literatura deve, portanto, ser lida e estudada porque oferece um meio [...] de preservar e transmitir a experiência dos outros, aqueles que estão distantes de nós no espaço e no tempo, ou que diferem de nós por suas condições de vida" (p. 47), fazendo assim com que possamos conhecer outras realidades e experiências. A literatura pode atuar, portanto, em um processo de desenvolvimento de um olhar para o outro a partir da compreensão de diferentes contextos 
sociais. A ótica freireana da palavra-mundo dialoga com este entendimento de literatura uma vez que a educação (ou a leitura da palavra-mundo) permite o alargamento da compreensão do mundo.

Compreendemos que a ideia de Compagnon dialoga, ainda, com a ideia de bell hooks (2020) de que a contação de história, seja ela ficcional ou verdadeira, nos conecta a outros mundos e a outras realidades. Ela pode acontecer de diferentes maneiras, não apenas por meio da literatura e da escrita, mas também por meio do diálogo e da conversação, contribuindo para o desenvolvimento de um pensamento crítico e reflexivo.

Nessa linha, bell hooks (2020) defende que o diálogo e o compartilhamento de histórias (ou a contação de histórias) são elementos ou componentes essenciais para o desenvolvimento do pensamento crítico. Este, por sua vez, é essencial para a compreensão do mundo pois, de acordo com a autora, "o cerne do pensamento crítico é o anseio por saber - por compreender o pensamento da vida" (p. 31). hooks (2020) defende que pensar criticamente é uma forma de compreender a realidade de maneira reflexiva. Para ela, o pensamento crítico nos leva a refletir e a indagar sobre o mundo em que vivemos e sobre o contexto em que estamos inseridos, pois:

todo mundo se envolve com o pensar na vida diária. Há várias situações enfrentadas por pessoas comuns que exigem que elas examinem a realidade para além do que é superficial [...] Essas situações podem levá-las a refletir sobre as questões relacionadas a quem, o quê, onde, quando, como e por quê (p. 279-280).

\section{Metodologia}

Este estudo tem como objetivo investigar o papel da literatura no processo de reflexão e desenvolvimento da consciência crítica no contexto do projeto de extensão "Nas Entrelinhas: literatura de autoria feminina no presídio feminino de Itajaí - SC" do Instituto Federal de Santa Catarina. Este projeto, que acontece desde 2019, tem como objetivo promover a reflexão crítica por meio da literatura de autoria feminina no presídio feminino de Itajaí, em que a leitura de diversas obras é realizada por meio do diálogo e da interação dos participantes do projeto. Neste artigo, buscamos compreender as contribuições que a leitura do livro "Redemoinho Em Dia Quente", de Jarid Arraes (2019), trouxe para a equipe proponente do projeto, formada por professores, discentes extensionistas e voluntários.

A equipe executora do projeto escolheu a obra de Jarid Arraes (2019) para ser lida como parte do projeto de extensão. A obra em questão reúne uma coletânea de contos, sendo a maioria deles narrados por mulheres. De acordo com Rodrigues (2020), o livro de Jarid Arraes "reflete a complexidade 
da mulher - do sertão, mas não só" (p. 2). O livro trata de histórias que retratam a vida, os dilemas, os problemas e as alegrias das mulheres do sertão do Cariri.

Primeiramente, os integrantes do projeto "Nas Entrelinhas" foram convidados a participar da pesquisa e tiveram acesso ao Termo de Consentimento Livre e Esclarecido. Tendo aceito o convite, convidamos os integrantes do projeto para participar de um grupo focal em que pudemos conduzir uma entrevista semiestruturada. Neste sentido, preparamos 5 perguntas para a discussão, que tinham objetivo principal de suscitar o debate e a reflexão acerca dos impactos pessoais gerados pela leitura do livro de Arraes. Este encontro aconteceu de forma online e remota, via plataforma Google Meet, haja vista o contexto de transmissão e disseminação do novo coronavírus.

O grupo focal contou com seis participantes, sendo eles: 2 professores, 3 estudantes e 1 voluntário, além dos 3 pesquisadores autores deste artigo. Os pesquisadores utilizaram um questionário semiestruturado de forma a guiar a conversa e suscitar o debate. As questões formuladas pelos pesquisadores deste presente artigo com o objetivo de investigar as respostas dos participantes foram: 1) Como foi a experiência de ler o livro da Jarid Arraes? Você acha que os contos trouxeram algum tipo de reflexão para a vida?; 2) Qual sentimento a leitura suscitou em você?; 3) Você consegue relacionar os contos da Jarid Arraes a questões e problemas sociais do Brasil contemporâneo?; 4) Você acha que os contos da Jarid Arraes poderiam ser histórias da contemporaneidade?; 5) Você já presenciou ou vivenciou alguma situação similar às apresentadas na história? Ou se identificou com alguma delas?. Todos os participantes respondiam às questões e aos tópicos sugeridos de forma livre, podendo dialogar com outros participantes do grupo sobre a obra em questão.

A entrevista/discussão foi gravada e posteriormente transcrita. Então, realizamos uma análise temática dos dados de forma a identificar quais temas emergiram no grupo focal. Estes temas foram avaliados pelos três pesquisadores, que fizeram sugestões de adequação e reagrupamento de categorias temáticas. Então, os dados foram analisados à luz da fundamentação teórica deste estudo. Para assegurar a privacidade e o direito ao anonimato dos participantes, usamos pseudônimos para identificá-los no processo de escrita deste artigo.

\section{Resultado e discussão}

Como já descrito anteriormente na seção de metodologia deste artigo, os dados apresentados para discussão e análise dos resultados foram obtidos por meio de uma discussão em um grupo focal. Após a coleta de dados, as falas dos participantes foram transcritas e depois categorizadas de acordo com os principais temas que surgiram na discussão deste grupo. A partir dessa categorização, foi 
possível identificar oito temas emergentes nas falas dos participantes, de modo a entender as reflexões advindas da experiência de leitura e de interação com a obra. Os temas foram organizados para fins de categorização, visando uma apresentação mais clara dos resultados, porém é preciso destacar que os temas se inter-relacionam e por vezes atuam de maneira conjunta ou mesmo complementar:

\begin{tabular}{|c|l|}
\hline Tema & \multicolumn{1}{|c|}{ Descrição: } \\
\hline 1 & $\begin{array}{l}\text { O(a) leitor(a) relata que a leitura suscitou sentimentos diversos. Entre eles, destacam-se os } \\
\text { sentimentos de felicidade, angústia e tristeza. }\end{array}$ \\
\hline $\mathbf{2}$ & O(a) leitor(a) relata uma leitura agradável e uma experiência pessoal positiva com a obra. \\
\hline $\mathbf{3}$ & O(a) leitor(a) relaciona a sua leitura com experiências pessoais. \\
\hline 4 & O(a) leitor(a) traz como referência em sua fala um conto específico da obra. \\
\hline $\mathbf{5}$ & $\begin{array}{l}\text { O(a) leitor(a) faz referência à fala de outro(a) participante do grupo e, a partir disso, constrói um } \\
\text { argumento/traz uma reflexão. }\end{array}$ \\
\hline $\mathbf{6}$ & O(a) leitor(a) estabelece uma relação entre sua leitura e questões sociais atuais. \\
\hline 7 & O(a) leitor(a) traz como referência em sua fala informações externas sobre o livro e a autora. \\
\hline $\mathbf{8}$ & O(a) leitor(a) relaciona a sua experiência de leitura com outras obras trabalhadas anteriormente por \\
Seu grupo.
\end{tabular}

Figura 1: Quadro descritivo dos temas emergentes.

Fonte: Elaborado pelos autores.

Como podemos observar, ao relatar a experiência de leitura os participantes destacam que os contos causaram diversas sensações e variadas experiências, tais como sentimentos de angústia, tristeza e felicidade, como descreve o tema 1, evidenciando como a obra atua de maneira diferente em cada leitor:

Esse foi um dos sentimentos que veio, dessa potência das mulheres, das histórias, das personagens. [...] Por mais que várias histórias me emocionaram bastante, também mostraram essa força da mulher (Participante Lúcia).

É doloroso né, tem histórias que são muito dolorosas e a gente não vê uma forma de solucionar (Participante Mara).

Então, o livro tem vários contos. Eu lia um conto e ficava super triste e no outro já era muito engraçado (Participante Dora).

De acordo com as falas dos participantes, é perceptível que a mesma obra gerou sentimentos diferentes nos leitores e, por vezes, sentimentos antagônicos. Ao passo que uma participante (Lúcia) expõe uma certa "potência" ao ler a obra, a participante Mara entende que a obra causou nela um certo 
desconforto ao citar que "tem histórias que são muito dolorosas e a gente não vê uma forma de solucionar". De acordo com Candido (1995), esse processo da literatura no inconsciente e subconsciente humano, tal como o sentimento, atua como um processo humanizador. Esse processo atua na reflexão, nos sentimentos e na percepção do mundo, e pode atuar de maneira diversa em cada leitor, visto que a realidade, a interpretação e as experiências de cada leitor são únicas.

É importante ressaltar que o livro de Jarid Arraes é uma coletânea de contos que retratam histórias diversas umas das outras e, ainda que os participantes tenham relatado sentimentos que retratam angústia e tristeza, a experiência de leitura da obra foi de forma geral positiva, como descrevemos no tema dois:

\footnotetext{
Então pra mim foi muito prazeroso porque a escrita dela é muito poética, muito bonita, é muito agradável de ler (Participante Ana).

A minha experiência foi muito positiva, eu fiquei bem interessada na leitura, foi um livro que me prendeu (Participante Mara).

É uma literatura acessível e democrática, com reflexões e histórias que fazem as mulheres no geral se sentirem representadas (Participante Dora).
}

Perante a isso, destacamos que a leitura da obra trouxe aos participantes a experiência positiva de vivenciar novas realidades, de modo que estes puderam refletir sobre a realidade e o contexto dos personagens presentes nas histórias. Essa percepção de outras realidades que acontece por meio da literatura "desenvolve em nós a quota de humanidade na medida que nos torna mais compreensivos e abertos para a natureza, a sociedade, o semelhante" (CANDIDO, 1995, p. 182).

Ainda de acordo com os participantes, é possivel perceber que a leitura não apenas suscitou sentimentos e trouxe a eles uma experiência que os levou para outras realidades, mas também oportunizou uma reflexão sobre sua própria existência, já que puderam relacionar sua vida com a experiência de leitura que a obra proporcionou, como descreve o tema três. Em vários momentos é possível identificar que a obra fez com que os participantes refletissem sobre elementos de suas vidas pessoais, relacionando-os com contos específicos da obra de Jarid Arraes (tema quatro):

Em alguns contos eu realmente consegui voltar pra minha infância, pro lugar onde eu morava,
e identificar nos personagens alguém da família, do bairro. Por exemplo, tem um conto que é
"Viração De Tempo", se eu não me engano, que fala da loucura que era uma moradora de rua,
algo assim, e na cidade em que eu cresci, Viamão no Rio Grande Do Sul, tinha sempre essas
pessoas. Tinha um homem que eu não lembro o nome, tinha uma mulher chamada Xuxa Da
Parada, tinha uma mulher que saiu sem roupa pela rua, perto da minha escola. Essa figura da
pessoa que mora na rua e que tem ali algum problema psicológico é uma figura que está
presente nas histórias urbanas e na minha infância tinha muito isso. Uma das coisas que eu via
na minha infância era que essas figuras eram usadas para amedrontar as crianças, que era
assim "ah, eu vou chamar fulano" que eu nem lembro, mas eu já era adolescente quando um LínguaTec, Instituto Federal de Educação, Ciência e Tecnologia do Rio Grande do Sul, Bento Gonçalves v. 6, n. 2 , p. 118-130, nov. 2021. 
desses homens morreu e houve uma grande mobilização dos adolescentes e jovens adultos por conta da morte dele. Isso era utilizado para amedrontar as crianças, "ah, eu vou chamar fulano" ou "ah, eu vou chamar a fulana", e aqui mostra o olhar da criança querendo ajudar, o olhar diferente para essa figura, e eu não lembro como era o meu olhar para essa situação, mas eu lembro de não ser de medo. Esse foi um dos contos que mais mexeu comigo por conta dessa relação da personagem apresentada no livro e das personagens que eu convivi na minha infância (Participante Dora).

Teve um conto que eu me emocionei muito que é o conto dos cachorros do quintal, que eles mais ou menos eram uma parte do quintal, secando até morrer. Eu tenho uma relação muito forte com animais, especialmente na minha infância, mexeu muito com as minhas histórias e minhas recordações apesar de ser um contexto diferente. Achei que ela conseguiu traduzir a partir de uma narradora que naturaliza o animal naquela situação "desumana", mas a partir do seu desenvolvimento crítico ela olha com outro olhar (Participante Mara).

Em ambas as respostas as participantes referem-se a contos distintos e a realidades distintas, porém trazem em suas falas uma relação da obra com experiências pessoais vividas por elas. $A$ participante Dora cita em sua resposta o conto "Viração de tempo" (ARRAES, 2019, p. 54-55), que narra a história de uma menina que mora na rua, e a relaciona com sua infância, trazendo elementos do contexto em que ela estava inserida com a realidade exposta na história. Ela afirma, por exemplo: "esse foi um dos contos que mais mexeu comigo por conta dessa relação da personagem apresentada no livro e das personagens que eu convivi na minha infância".

A participante Mara cita em sua fala o conto "Cachorro de quintal" (ARRAES, 2019, p. 37-40) em que a narradora fala sobre sua infância e traz reflexões sobre a forma que sua família enxergava e tratava seus cachorros -, e explica como a leitura atuou de maneira sentimental e crítica nela: "Achei que ela conseguiu traduzir a partir de uma narradora que naturaliza o animal naquela situação 'desumana', mas a partir do seu desenvolvimento crítico ela olha com outro olhar". A participante Mara, assim como a participante Dora, faz uma relação entre texto e contexto, e cita como o texto atuou de forma a compreender de maneira crítica aquele contexto em que estava inserida. Freire (1989) explica que essa relação do texto com o contexto proporciona ao leitor uma leitura crítica do mundo pois, de acordo com 0 autor, "linguagem e realidade se prendem dinamicamente. A compreensão do texto a ser alcançada por sua leitura crítica implica a percepção das relações entre o texto e o contexto" (p. 9). Isto é, a leitura tem um papel formador na racionalização crítica e na compreensão de mundo, atuando como uma ponte entre literatura/leitura e realidade.

Neste sentido, é perceptível a relação entre os quatro primeiros temas emergentes descritos neste artigo. Também é importante destacar, com base nestes temas, que a maneira que a leitura de uma obra atua em cada leitor depende de vários fatores, tais como a percepção de mundo, a experiência de vida e o possível laço emocional que a obra suscita. 
Ao analisarmos o quinto tema emergente, podemos perceber como a leitura de uma mesma obra, com posterior organização de um grupo focal, promoveu reflexão e discussão de modo que os participantes interagissem e construíssem argumentos e reflexões de maneira conjunta, mas também de maneira diversa. Como exemplo disso temos uma discussão que gerou debate entre duas participantes, Lúcia e Dora, que refletiram sobre o conto "Telhado quebrado com gente morando dentro" (ARRAES, 2019, p. 32-36). Este conto trata da história da relação entre duas irmãs na adolescência, em que uma delas (Juliana) é abusada sexualmente por seu pai:

\begin{abstract}
Eu marquei um texto aqui de um dos contos que eu gostei muito, que é o "Telhado quebrado com gente morando dentro". O título do texto é esse. Esse título, no caso, tem um trecho que ela fala "mas quando ela chegou na casa da avó, não parecia me odiar ou achar que eu era responsável por tudo o que aconteceu. Não sei se ela pensava em Túlio, se a cabeça dela tinha espaço para isso. Eu olhei para os olhos da minha irmã e vi uma Juliana ainda mais velha do que aquela que eu conhecia. Não era mais a garota que tinha muita força. Era uma casa com telhado quebrado, mas com gente ainda morando dentro." É de uma potência, eu acho muito muito potente os textos dela. A escolha do título, ela faz essa analogia da irmã, e quando ela olha nos olhos da irmã, mesmo, apesar de tudo que aconteceu, é uma casa né, que o telhado tá quebrado, mas tem gente ainda morando dentro. Esse foi um dos sentimentos que veio, dessa potência das mulheres, das histórias, das personagens (Participante Lúcia)
\end{abstract}

$\mathrm{Na}$ fala, a participante Lúcia descreve como o conto atuou nela de forma positiva, de forma "potente", como explicita a participante. De acordo com ela, o trecho citado do conto é um exemplo de como essa potência feminina é positiva "apesar de tudo que aconteceu" na história. Em contrapartida, trazemos a fala da participante Dora, que cita a fala da participante Lúcia e traz uma reflexão contrária sobre o mesmo conto:

Eu ouvi a Lúcia falando do conto que eu nem lembrava mais, Telhado quebrado com gente morando dentro. E aí, quando tu fala, Lúcia, que tu sente uma potência né, da Juliana... enfim, uma potência da mulher. Quando a gente fala na potência, eu sempre penso em alguma coisa positiva. Algo assim extremamente positivo. Mas quando eu li esse conto, eu não senti esse telhado quebrado com gente morando dentro como alguma coisa positiva. Eu senti assim, como algo negativo mesmo. Eu pensei num zumbi. Tá ali fazendo o que tem que fazer, vivendo do jeito que tem, Só que não tem mais vida... Por exemplo, um telhado quebrado com gente morando dentro. Eu penso que um telhado quebrado não serve mais para proteger as pessoas que estão morando dentro. Mas as pessoas continuam morando sem pensar que o telhado não está mais ali. E eu pensei na Juliana assim, a Juliana não está mais ali, mas ela continua ali. Ela vai ficar transitando a vida inteira dela ali, fazendo as coisas que se esperam que ela faça, como se o telhado tivesse lá, mas o telhado não está mais lá. Então eu pensei nisso como uma coisa negativa. E quando a Lúcia fala "potência" eu penso em algo muito positivo que eu nem consigo imaginar nessa situação. Não sei se foi nesse sentido que a Lúcia falou em potência, mas eu fico com receio de pensar que o fato de ela estar ali vivendo, parecendo um telhado quebrado mas com gente morando dentro... Enfim... Se a gente pode interpretar isso como uma coisa positiva. "Nossa que maravilhosa, ela continuou vivendo e é uma guerreira" mas não né, ela não sabe o que fazer. Se ela pudesse escolher, eu acho que ela não escolheria ficar ali porque ela não sabe o que fazer. Ninguém sabe, nem uma mulher do convívio dela sabe o que fazer. Elas vão saber viver ali, mas elas não sabem o que elas querem. Eu pensei nisso ouvindo 
a Lúcia, e eu nem lembrava muito desse conto. É um conto muito marcante para mim, muito marcante mesmo. Lembro do momento que eu li, chorei horrores (Participante Dora).

Em sua fala, a participante Dora traz uma reflexão contrária à reflexão da participante Lúcia, citando como o mesmo conto trouxe para ela um sentimento negativo, de tristeza e angústia. $\mathrm{A}$ participante Dora faz referência à fala da participante Lúcia e a partir dela traz uma análise do seu ponto de vista sobre o mesmo conto, em que ela afirma:

[...] quando tu fala, Lúcia, que tu sente uma potência né, da Juliana... enfim, uma potência da mulher. Quando a gente fala na potência, eu sempre penso em alguma coisa positiva. [...] Mas quando eu li esse conto, eu não senti [...] como alguma coisa positiva. Eu senti assim, como algo negativo mesmo.

Ao escutar a reflexão da participante Dora, a participante Lúcia revela que não tinha observado esse ponto de vista contrário, mas que a fala da participante Dora trouxe para ela outra ótica sobre o mesmo conto:

\begin{abstract}
A minha fala foi "potência" do ponto de vista positivo mesmo... Mas achei bem interessante o olhar que tu trouxe. Quando eu estava lendo, refleti bastante sobre várias situações ao redor [...] como é que tu ressignifica, sabe, como consertar o telhado que quebrou. Eu olhei a partir dessa perspectiva. $O$ telhado quebrou mesmo, mas ainda tem gente ali. Foi mais desse olhar. Mas faz total sentido o que tu trouxe também. É muito forte né, é um conto muito forte. Obrigada por trazer esse outro olhar. (Participante Lúcia).
\end{abstract}

No entanto, mesmo com visões contrárias, as participantes compartilharam seu ponto de vista, e essa troca de compreensões trouxe às participantes uma experiência que não teria sido desenvolvida se esse diálogo não acontecesse, como cita a participante Lúcia: "A minha fala foi 'potência' do ponto de vista positivo mesmo... Mas achei bem interessante o olhar que tu trouxe", evidenciando essa troca de conhecimento. bell hooks afirma que essa troca de informações, também chamada de colaboração, "nos permite ter uma visão mais expansiva do mundo" (p. 73) pois, de acordo com ela, "ao escolher e nutrir o diálogo, nós nos envolvemos mutuamente em uma parceria na aprendizagem" (p. 81). Isso significa que, de acordo com a autora, a conversação e cooperação aguçam nosso pensamento crítico, pois essa troca de conhecimento nos ajuda a compreender melhor o mundo em que vivemos.

Além dos primeiros cinco temas que, como pudemos perceber, estão inter-relacionados, também foi possivel identificar outras três categorias emergentes nas falas dos participantes. Perante a isso, apontamos o sexto tema, em que os participantes relacionam a leitura da obra com questões sociais atuais: 
Tem essas pinceladas que envolvem o leitor mas no fim acho que é mais um tapa mostrando as dificuldades, especialmente a questão de gênero. É isso, eu acho que as reflexões pra vida partem dessa experiência, de como ser mulher às vezes significa levar nossa trajetória a momentos de você estar vulnerável, de perigo mesmo, e o quanto isso precisa mudar. A gente sabe que isso é dos nossos dias (Participante Mara).

Bom, eu separei um [...] conto, "Got a flamin' heart, can't get my fill" e ele me chamou atenção pelo momento que a gente está passando nessa pandemia e de isolamento social [...] Ele retrata a angústia de uma pessoa com depressão, e como ela se perde dela mesma e como é um momento de sofrimento e solidão. Quando eu li eu consegui sentir como se eu estivesse no lugar dela, porque com esse isolamento social a gente acaba ficando meio sozinho, não consegue sair de casa pra inventar muita coisa e é difícil... (Participante Luís).

Nas falas, os participantes relataram questões sociais tratadas pelo livro, como a fala da participante Mara, relacionada ao gênero, e outra do participante Luís, relacionada à depressão, em que ele cita o conto "Got a flamin' heart, can't get my fill" (ARRAES, 2019, p. 49-53). Este conto trata da história de Luana, a narradora-personagem, que nos conta sobre sua vida e seus desejos incessantes de morrer. Os participantes, ao lerem a obra, estabeleceram uma relação entre os contos presentes no livro e a realidade em que estão inseridos. Candido propõe que "[...] a literatura satisfaz, em outro nível, à necessidade de conhecer os sentimentos e a sociedade, ajudando-nos a tomar posição em face deles" (1988, p. 182-183), afirmando que a literatura nos ajuda a compreender (e quiçá agir com relação a) problemas sociais.

A participante Mara, em sua fala, destaca a vulnerabilidade social relacionada à questão de gênero e os perigos que a mulher enfrenta na sociedade ao afirmar que "[...] É isso, eu acho que as reflexões pra vida partem dessa experiência, de como ser mulher às vezes significa levar nossa trajetória a momentos de você estar vulnerável, de perigo mesmo, e o quanto isso precisa mudar [...]". De acordo com Resk (2021), em "meio à pandemia de covid-19 no Brasil, uma a cada quatro mulheres a partir dos 16 anos afirma ter sido vítima de algum tipo de violência nos últimos 12 meses" (p. 1-5). Entre as situações de violência, destacam-se as agressões verbais, físicas e sexuais.

O participante Luís destaca em sua fala um problema social relacionado a questões psíquicas, mais especificamente a depressão. O participante Luís, assim como a participante Mara, destaca além de um problema social, uma experiência pessoal, ao afirmar que:

[...] ele me chamou atenção pelo momento que a gente está passando nessa pandemia e de isolamento social [...] Ele retrata a angústia de uma pessoa com depressão, e como ela se perde dela mesma e como é um momento de sofrimento e solidão. Quando eu li eu consegui sentir como se eu estivesse no lugar dela, porque com esse isolamento social a gente acaba ficando meio sozinho [...] (grifo nosso). 
O participante Luís, a partir da sua leitura, relacionou a pandemia do coronavírus e o isolamento social como um fator para a depressão, uma questão psíquica que se tornou um problema social. De acordo com Félix (2021), um "levantamento inédito do Conselho Federal de Farmácia (CFF) apontou um aumento de $17 \%$ nas vendas de antidepressivos e estabilizadores de humor em 2020, primeiro ano da pandemia de covid-19" (p. 1), pois, ainda de acordo com a jornalista, "mudanças na rotina, incertezas e o isolamento social estão entre fatores que levaram mais pessoas aos consultórios de psiquiatras" (2021, p. 1-2). Isto é, a partir da leitura da obra, os participantes relacionaram a sua leitura com problemas sociais presentes na realidade dos mesmos, gerando reflexão acerca do mundo e da realidade em que vivem.

Já o tema sete aponta que os participantes também trouxeram outras referências em suas falas, como informações externas sobre o livro e a autora. Mais especificamente, alguns participantes mencionaram entrevistas e a forma de escrita da autora:

\footnotetext{
Eu assisti uma entrevista da Jarid em que ela fala que a literatura é sempre política, e que ter consciência disso faz toda a diferença (Participante Rita).

Eu também vi uma entrevista dela onde ela fala que a principal, ou talvez uma das principais referências pra ela é a Lady Gaga (Participante Mara).
}

As falas das participantes retratam a relação entre a literatura escrita por Jarid Arraes e a cultura pop, ao citar a cantora Lady Gaga, evidenciando uma conexão entre a literatura e a realidade. É possível perceber que os participantes, ao relacionarem a obra de Jarid Arraes com outras informações externas ao livro, conectam diferentes contextos que permitem a eles refletirem de maneira mais ampla sobre sua leitura.

O oitavo tema aponta para falas dos participantes relacionadas a experiência de leitura, mais especificamente no que diz respeito a referências a outras obras trabalhadas anteriormente pelo grupo em questão. É preciso destacar que os participantes do grupo focal compõem a equipe executora de um projeto de extensão, cujas atividades incluem a discussão de obras literárias de autoria feminina. Assim, a cada mês os participantes leem um livro e o debatem. Como exemplo, temos a fala de Mara:

De certa maneira ele dialogou bastante com os livros que a gente tem lido, especialmente a da Martha (Martha Batalha) que a gente terminou de ler agora [..] (Participante Mara).

Mara estabelece relações com demais livros lidos pelo grupo, evidenciando assim a construção de um repertório literário. De certo modo, as leituras selecionadas pelo grupo estão conectadas, visto que os livros lidos são de autoria feminina, gerando assim discussões relacionadas à questão social de 
gênero. A escritora bell hooks defende que 0 ato de ler deve ser um exercício constante (e no caso específico dos participantes deste artigo, ler livros de autoria feminina) porque "ler permite a todo cidadão desta nação e do mundo assumir responsabilidade cívica. É impossível sermos agentes adequados de nosso ambiente, cuidando de nós mesmos e do mundo, sem a habilidade de ler" (2020, p. 203). Além disso, a leitura oferece uma possibilidade de se conectar com um mundo para além de si mesmo, ou seja, para outras realidades. Portanto, podemos dizer que o fato do grupo ler diferentes obras - e de forma constante - para então discuti-las de forma conjunta também pode ser entendido como importante para o desenvolvimento do pensamento e da reflexão crítica, já que assim conseguem estabelecer conexões, relações e ampliar seus repertórios literários e culturais.

\section{Considerações finais}

Considerando os dados analisados, podemos perceber, portanto, que os participantes puderam refletir sobre questões sociais e sobre suas experiências e vivências a partir da leitura de "Redemoinho em dia quente" (ARRAES, 2019). Para além disso, o encontro de discussão da obra oportunizou que diferentes visões pudessem ser expostas e/ou contrapostas, enriquecendo, complementando ou mesmo ressignificando os repertórios e as reflexões de cada participante. Destacamos, neste sentido, que o pensamento crítico (HOOKS, 2020) é desenvolvido por um processo contínuo de reflexão, discussão e envolvimento com a realidade (envolvimento este que não é apenas racional, mas também emocional, já que diz respeito também às nossas subjetividades). Deste modo, pudemos perceber que não somente o contato com a literatura e a leitura, mas principalmente o diálogo e a troca propiciaram aos participantes da pesquisa a possibilidade de engajamento em um processo de desenvolvimento crítico.

Frente à potencialidade da literatura e do diálogo no processo de desenvolvimento do pensamento crítico, defendemos a importância de fomentar trabalhos como 0 do projeto de extensão analisado em todos os campos sociais, das mais diversas áreas, por meio de espaços e grupos de leitura, de modo que ela se torne acessível e presente na vida de todo cidadão, tornando-se, conforme defende Candido (1995), um direito humano.

\section{Referências}

ARRAES, J. Redemoinho em dia quente. Rio de Janeiro, RJ: Alfaguara, 2019.

CANDIDO, A. Vários Escritos: o direito à literatura. São Paulo, SP: Duas Cidades, 1995.

COMPAGNON, A. Literatura para quê? Belo Horizonte, MG: UFMG, 2009. Tradução de: Laura Taddei 
Brandini.

FELIX, P. Venda de antidepressivo cresce 17\% na pandemia, diz Conselho Federal de Farmácia. 0 Estado de S. Paulo. São Paulo, p. 1-6. 01 mar. 2021. Disponível em: https://saude.estadao.com.br/noticias/geral,venda-de-antidepressivo-cresce-17-na-pandemia-dizconselho-federal-de-farmacia,70003631942. Acesso em: 10 ago. 2021.

FREIRE, P. A importância do ato de ler: em três artigos que se completam. São Paulo, SP: Autores Associados: Cortez, 1989.

HOOKS, B. Ensinando pensamento crítico: sabedoria prática. São Paulo, SP: Elefante, 2020.

PERISSÉ, G. Literatura \& Educação. Belo Horizonte: Autêntica, 2007.

RESK, F. Uma a cada quatro mulheres foi vítima de violência no último ano, aponta pesquisa. O Estado de S. Paulo. São Paulo, p. 1-5. 07 jun. 2021. Disponível em: https://brasil.estadao.com.br/noticias/geral,uma-a-cada-quatro-mulheres-foi-vitima-de-violencia-noultimo-ano-aponta-pesquisa,70003738858. Acesso em: 10 ago. 2021.

RODRIGUES, M. F. Um Livro Por Semana \#15: todas as vozes ('Redemoinho em Dia Quente'). O Estado de S. Paulo. São Paulo, p. 1-4. 27 jun. 2020. Disponível em:https://cultura.estadao.com.br/blogs/babel/um-livro-por-semana-15-todas-as-vozes-redemoinho-emdia-quente/. Acesso em: 10 ago. 2021.

Data de submissão: 13/09/2021. Data de aprovação: 24/10/2021. 